\title{
Analisis Soal Dalam Buku Siswa Matematika Kurikulum 2013 Untuk Sekolah Menengah Pertama Kelas VII Berdasarkan Dimensi Kognitif Trends International Mathematics and Science Study (TIMSS) (Analysis of Test Items in Student Mathematics Text Book 2013 Curriculum for Junior High School VII ${ }^{\text {th }}$ Grade Based on Cognitive Dimensions Trends International Mathematics And Science Study (TIMSS))
}

\author{
Yayuk Kuswanti, Susi Setiawani, Nurcholif Diah Sri Lestari, \\ Pendidikan Matematika, Fakultas Keguruan dan Ilmu Pendidikan, Universitas Jember (UNEJ) \\ Jln. Kalimantan 37, Jember 68121 \\ E-mail: susi.fkip@unej.ac.id
}

\begin{abstract}
Abstrak
Tujuan penelitian ini adalah untuk mendeskripsikan soal matematika dalam Buku Siswa Matematika Kurikulum 2013 untuk Sekolah Menengah Pertama (SMP) Kelas VII berdasarkan dimensi kognitif Trends International Mathematics And Science Study (TIMSS). Metode penelitian yang digunakan adalah deskriptif, dengan subjek penelitian adalah soal uji kompetensi dalam Buku Siswa Matematika Kurikulum 2013 untuk SMP kelas VII semester 1 (edisi revisi 2014) yang disusun dan ditelaah oleh berbagai pihak di bawah koordinasi Kementerian Pendidikan dan Kebudayaan dan diterbitkan oleh Pusat Kurikulum dan Perbukuan, Balitbang, Kemdikbud. Pengumpulan data yang dilakukan menggunakan metode dokumentasi dan metode angket. Pedoman yang digunakan pada analisis soal adalah deskriptor pada setiap domain berdasarkan dimensi kognitif TIMSS. Hasil penelitian menunjukkan bahwa soal yang dianalisis memuat 2,82 \% deskriptor A2 (mengenali), 7,35\% deskriptor A3 (menghitung), 12,43\% deskriptor (mengambil), 16,38\% deskriptor (mengklasifikasikan/mengurutkan), 25,4\% deskriptor B1 (memilih), 9,6\% deskriptor B2 (menunjukkan), 7,35\% deskriptor B3 (memodelkan), 0,6\% deskriptor B4 (mengimplementasikan), 7,9\% deskriptor B5 (memecahkan masalah rutin), 3,38\% deskriptor $\mathrm{Cl}$ (menganalisis), 4,52\% deskriptor C3 (mengintegrasikan/menyatukan), 1,69\% deskriptor C4 (membenarkan) dan 0,6\% lain-lain. Secara keseluruhan berdasarkan dimensi kognitif TIMSS soal yang termasuk domain penerapan memiliki persentase paling tinggi yaitu sebesar $50,85 \%$, diikuti dengan domain pengetahuan yaitu sebesar $38,98 \%$, dan paling sedikit termasuk domain penalaran yaitu sebesar $9,6 \%$.
\end{abstract}

Kata Kunci: Dimensi Kognitif, TIMSS, Domain Pengetahuan, Domain Penerapan, Domain Penalaran.

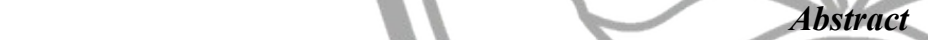

The aim of this research is to describe the test items in Student Mathematics Text Book 2013 Curriculum for Junior High School (SMP) Grade VII th by using Cognitive Dimensions Trends International Mathematics And Science Study (TIMSS). The method of this research is descriptive, with the research subject is competency tests in the Student Mathematics Text Book 2013 Curriculum for junior grade VII ${ }^{\text {th }}$ Semester 1 (revised edition 2014) were prepared and analyzed by various parties under the coordination of the Ministry of Education and Culture and published by the Center for Curriculum and of Books, Research, Kemendikbud. Data collection was performed by using documentation and questionnaire method. Guidelines used in the item analysis is based on the descriptors on each domain TIMSS cognitive dimension. The results show that the problem being analyzed contains 2,82\% descriptor A2 (recognize), 7,35\% descriptor A3 (compute), 12,43\% descriptor $A 4$ (retrieve), 16,38\% descriptor A6 (classify/order), 25,4\% descriptor B1 (select), 9,6\% descriptor B2 (represent), 7,35\% descriptor B3 (model), 0,6\% descriptor B4 (implement), 7,9\% descriptor B5 (solve routine problems), 3,38\% descriptor C1 (analyze), 4,52\% descriptor C3 (integrate/synthesize), 1,69\% descriptor C4 (justify) and 0,6\% other. Overall, based on the cognitive dimensions TIMSS, the test items that included applying domain have the highest percentage of 50,85\% which followed by knowing domain with percentage of 38,98\%, and at least reasoning domain with percentage of $9,6 \%$.

Keywords: Cognitive Dimensions, TIMSS, Knowing, Applying, Reasoning .

\section{Pendahuluan}

Matematika merupakan pengetahuan dasar yang diperlukan oleh siswa untuk menunjang keberhasilan belajarnya dalam menempuh pendidikan yang lebih tinggi. Secara umum matematika diperlukan oleh semua orang dalam kehidupan sehari-hari. Oleh karena itu sangat diharapkan, siswa sekolah menengah untuk menguasai pelajaran matematika karena matematika merupakan sarana berpikir ilmiah yang sangat diperlukan oleh siswa.

Jika membahas tentang pembelajaran matematika di sekolah, hal itu tidak dapat dipisahkan dari peran kurikulum. Kurikulum adalah seperangkat rencana dan pengaturan 
mengenai isi dan bahan pelajaran serta cara yang digunakan sebagai pedoman penyelenggaraan kegitan belajar mengajar [1]. Kurikulum di Indonesia mengalami perubahan dari tahun ke tahun. Saat ini kurikulum yang berlaku di Indonesia adalah kurikulum 2013.

Kurikulum 2013 memiliki tujuan mempersiapkan manusia Indonesia agar memiliki kemampuan hidup sebagai pribadi dan warga negara yang beriman, produktif, kreatif, inovatif, dan afektif serta mampu berkontribusi pada kehidupan bermasyarakat, berbangsa, bernegara, dan peradaban dunia. Salah satu alasan dicetuskannya Kurikulum 2013 adalah pencapaian anak-anak Indonesia dalam TIMSS. Pencapaian anak-anak Indonesia yang tidak menggembirakan dalam beberapa kali laporan yang dikeluarkan TIMSS disebabkan antara lain banyaknya materi uji yang ditanyakan di TIMSS tidak terdapat dalam kurikulum Indonesia.

Sejak mengikuti TIMSS 1999 sampai TIMSS 2011, Indonesia selalu mendapatkan skor di bawah skor rata-rata internasional. Pada TIMSS 1999, siswa Indonesia menduduki peringkat 34 dari 38. Skor rata-rata yang diperoleh adalah 403, sedangkan skor rata-rata internasional adalah 487 [2]. Selanjutnya pada TIMSS 2003, siswa Indonesia menduduki peringkat 34 dari 45 negara. Skor ratarata yang diperoleh adalah 422 , sementara skor rata-rata internasional adalah 467 [3]. Pada TIMSS 2007, siswa Indonesia menduduki peringkat 36 dari 49 negara. Skor ratarata yang diperoleh adalah 397 , sementara skor rata-rata internasional adalah 500 [4]. Pada TIMSS 2011, siswa Indonesia menduduki peringkat 38 dari 42 negara. Skor ratarata yang diperoleh adalah 386 , sementara skor rata-rata internasional adalah dibawah 500 [5]. Hasil tersebut yang memaksa pendidikan di Indonesia harus berbenah agar tak tertinggal dari Negara lain.

Dalam rangka pembenahan pendidikan di Indonesia, pengembangan Kurikulum 2013 benar-benar dipersiapkan dengan baik oleh Pemerintah. Hal itu terbukti dalam pegaplikasian Kurikulum 2013, Pemerintah memberikan sarana yang dapat menunjang terselenggaranya Kurikulum 2013 yaitu dengan buku siswa. Kurikulum 2013 pada tahun 2014 dilaksanakan di kelas I, II, IV dan V untuk jenjang Sekolah Dasar/Madrasah Ibtidaiyah, kelas VII dan VIII untuk jenjang Sekolah Menengah Pertama/Madrasah Tsanawiyah, serta kelas X dan XI untuk jenjang Sekolah Menengah Atas/Sekolah Menengah Kejuruan/Madrasah Aliyah [6]. Dalam perjalanan keikutsertaan Indonesia pada penilaian internasional TIMSS, Indonesia hanya mengikutsertakan kelas VIII (usia 14 tahun). Maka, dibutuhkan analisis soal dalam buku siswa Kurikulum 2013 untuk Sekolah Menengah Pertama berdasarkan dimensi kognitif TIMSS, salah satunya untuk kelas VII. Hal itu dilakukan untuk mengetahui kesesuaian soal yang ada dalam buku siswa terhadap target yang ingin dicapai dimensi kognitif TIMSS dan tujuan pelaksanaan Kurikulum 2013. Adapun hasil dari penelitian, diharapkan dapat digunakan untuk perbaikan pendidikan di Indonesia.

Penelitian ini dilakukan untuk mendeskripsikan persentase soal dalam Buku Siswa Matematika Kurikulum 2013 untuk sekolah menengah pertama kelas VII yang sesuai deskriptor pada setiap domain berdasarkan dimensi kognitif
Trends International Mathematics and Science Study (TIMSS). Selain itu, penelitian ini juga dilakukan untuk mendeskripsikan persentase soal dalam Buku Siswa Matematika Kurikulum 2013 untuk sekolah menengah pertama kelas VII pada masing-masing domain berdasarkan dimensi kognitif Trends International Mathematics and Science Study (TIMSS).

Adapun manfaat yang diharapkan dalam penelitian ini adalah untuk membantu guru khususnya guru matematika kelas VII dalam memilih soal berdasarkan dimensi kognitif siswa. Penelitian ini juga dapat menambah pengalaman dalam meningkatkan wawasan sebagai calon guru, yaitu dalam hal pemilihan dan pembuatan soal yang sesuai dengan dimensi kognitif siswa. Selain itu, hasil dari penelitian ini dapat digunakan sebagai referensi dalam melakukan penelitian yang sejenis.

\section{Metode Penelitian}

Jenis penelitian ini adalah penelitian deskriptif. Metode pengumpulan data yang digunakan adalah metode dokumentasi dan metode angket. Data yang dianalisis adalah data hasil validasi deskriptor dan hasil analisis soal berdasarkan dimensi kognitif TIMSS. Waktu penelitian mulai dari mengklasifikasi soal dan analisis soal dilakukan pada bulan Agustus hingga Oktober 2014.

Pada penelitian ini, peneliti bertindak sebagai instrumen utama yaitu sebagai perencana, pelaksana pengumpul data, penganalisis data, penafsir data, dan pelapor hasil penelitian. Peneliti menggunakan instrumen pendukung berupa lembar validasi deskriptor, lembar deskriptor dan lembar klasifikasi. Untuk mendapatkan deskripsi soal pada Buku Siswa Matematika Kurikulum 2013 untuk Sekolah Menengah Pertama Kelas VII semester 1 (edisi revisi 2014) yang diterbitkan Kementerian Pendidikan dan Kebudayaan Republik Indonesia berdasarkan dimensi kognitif TIMSS digunakan langkah-langkah yang diperlihatkan pada Gambar 1 berikut.

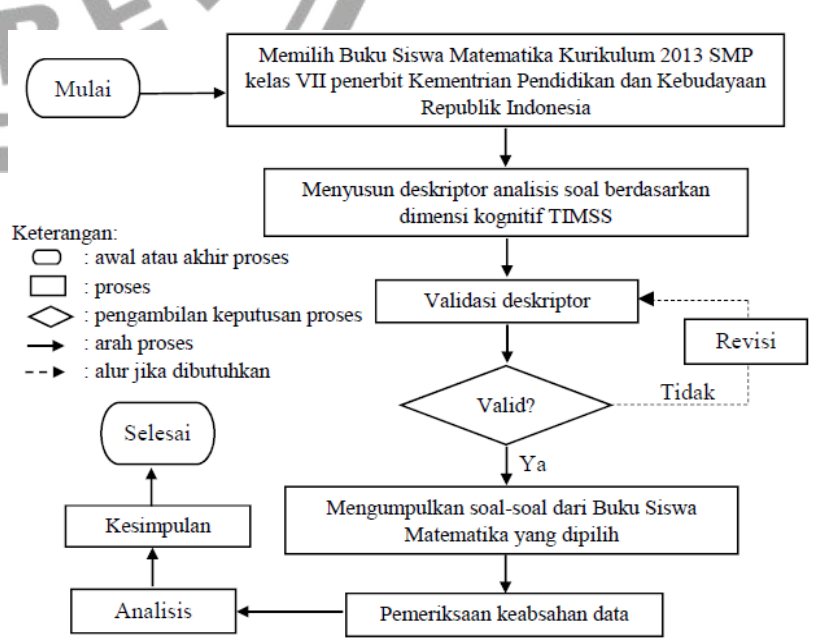

Gambar 1 Prosedur Penelitian

Adapun analisis data yang dilakukan adalah sebagai berikut.

i. Menentukan persentase banyaknya soal yang sesuai deskriptor pada setiap domain berdasarkan dimensi 
kognitif TIMSS) digunakan rumus:

$$
P_{i, j}=\frac{f_{i, j}}{N} \times 100 \%
$$

Keterangan :

$P_{i, j}=$ persentase banyaknya soal dimensi ke- $i$ aspek ke- $j$ untuk masing-masing deskriptor

$f_{i, j}=$ jumlah soal dimensi ke- $i$ aspek ke- $j$ untuk masingmasing deskriptor

$N=$ jumlah seluruh soal yang dianalisis

$i=1,2,3$

$j=1,2,3,4,5$ atau 6

ii. Menentukan persentase banyaknya soal untuk masingmasing domain berdasarkan dimensi kognitif TIMSS digunakan rumus:

$$
P_{i}=\frac{f_{i}}{N} \times 100 \%
$$

Keterangan :

$P_{i}=$ persentase banyaknya soal dimensi ke- $i$

$f_{i}=$ jumlah soal dimensi ke $i$

$N=$ jumlah seluruh soal yang dianalisis

\section{Pembahasan}

Berdasarkan data hasil validasi deskriptor didapat nilai rerata total yakni 3,36, maka hasil validasi deskriptor domain berdasarkan dimensi kognitif TIMSS termasuk ke dalam kategori valid. Pada kategori valid, maka perlu dilakukan revisi pada deskriptor namun tidak perlu dilakukan validasi kembali. Setelah itu dilakukanlah uji keabsahan data dengan penyidik. Kemudian hasil uji keabsahan data tersebut digunakan sebagai acuan untuk pengklasifikasian soal. Adapun persentase masing-masing pertanyaan yang terdapat dalam buku siswa matematika Kurikulum 2013 kelas VII untuk setiap dimensi kognitif TIMSS dapat dilihat pada Tabel 1.

Tabel 1 Persentase banyaknya soal untuk masing-masing dimensi kognitif TIMSS

\begin{tabular}{|c|c|c|c|c|c|c|c|c|c|c|}
\hline \multirow{2}{*}{ Soal } & \multirow{2}{*}{$\mathrm{n}$} & \multirow{2}{*}{$\mathrm{N}$} & \multicolumn{2}{|c|}{$\mathrm{A}$} & \multicolumn{2}{|c|}{$\mathrm{B}$} & \multicolumn{3}{|c|}{$\mathrm{C}$} & \multicolumn{2}{|c|}{ Lain-lain } \\
\cline { 4 - 11 } & & & $\mathrm{f}$ & $\%$ & $\mathrm{f}$ & $\%$ & $\mathrm{f}$ & $\%$ & $\mathrm{f}$ & $\%$ \\
\hline 1 & 26 & 39 & 8 & 4,52 & 29 & 16,38 & 2 & 1,13 & 0 & 0 \\
\hline 2 & 5 & 26 & 5 & 2,82 & 20 & 11,3 & 1 & 0,6 & 0 & 0 \\
\hline 3 & 12 & 25 & 16 & 9,04 & 6 & 3,39 & 3 & 1,69 & 0 & 0 \\
\hline 4 & 3 & 10 & 4 & 2,26 & 2 & 1,13 & 4 & 2,26 & 0 & 0 \\
\hline Smstr 1 & 39 & 77 & 36 & 20,34 & 33 & 18,65 & 7 & 3,9 & 1 & 0,6 \\
\hline Jumlah & 85 & 177 & 69 & 38,98 & 90 & 50,85 & 17 & 9,6 & 1 & 0,6 \\
\hline
\end{tabular}

Keterangan:

$\mathrm{A}=$ Domain Pengetahuan

$\mathrm{B}=$ Domain Penerapan

$\mathrm{C}=$ Domain Penalaran

$\mathrm{f}=$ Frekuensi (banyaknya pertanyaan)

$\mathrm{n}=$ Banyak Soal

$\mathrm{N}=$ Banyak Pertanyaan

$1=$ Uji Kompetensi 1

$2=$ Uji Kompetensi 2

$3=$ Uji Kompetensi 3

4 = Uji Kompetensi 4

Smstr 1= Uji Kompetensi Semester 1
Setelah dilakukan perhitungan persentase banyaknya soal untuk masing-masing dimensi kognitif TIMSS, tahap selanjutnya adalah mengelompokkan pertanyaan yang sesuai deskriptor pada setiap domainnya. Adapun hasil yang diperoleh dapat dilihat pada Tabel 2

Tabel 2 Persentase Banyaknya Soal yang sesuai Deskriptor pada Setiap Domain Berdasarkan Dimensi Kognitif

\begin{tabular}{|c|c|c|c|c|c|c|c|c|c|c|}
\hline $\begin{array}{l}\text { Dimensi } \\
\text { Kognitif }\end{array}$ & Deskriptor & $\mathrm{N}$ & f & $\%$ & $\mathrm{f}$ & $\%$ & $\mathrm{f}$ & $\%$ & $\mathrm{f}$ & $\%$ \\
\hline \multirow{18}{*}{ A } & 1 & 0 & 0 & 0 & & & & & & \\
\hline & 2 & 5 & 5 & 2,82 & & & & & & \\
\hline & 3 & 13 & 13 & 7,35 & & & & & & \\
\hline & 4 & 22 & 22 & 12,43 & & & & & & \\
\hline & 5 & 0 & 0 & 0 & & & & & & \\
\hline & 6 & 29 & 29 & 16,38 & & & & & & \\
\hline & 1 & 45 & & & 45 & 25,4 & & & & \\
\hline & & 17 & & & 17 & 9,6 & & & & \\
\hline & & 13 & & & 13 & 7,35 & & & & \\
\hline & & & & & 1 & 0,6 & & & & \\
\hline & & 14 & & & 14 & 7,9 & & & & \\
\hline & & & & & & & 6 & 3,38 & & \\
\hline & & 0 & & & & & 0 & 0 & & \\
\hline & 3 & 8 & & & & & 8 & 4,52 & & \\
\hline & & 3 & & & & & 3 & 1,69 & & \\
\hline & & 0 & & & & & 0 & 0 & & \\
\hline & & 1 & & & & & & & 1 & 0,6 \\
\hline & & 177 & 69 & 38,98 & 90 & 50,85 & 17 & 9,6 & 1 & 0,6 \\
\hline
\end{tabular}
TIMSS

Keterangan:

$\mathrm{A}=$ Domain Pengetahuan

$\mathrm{B}=$ Domain Penerapan

$\mathrm{C}=$ Domain Penalaran

$\mathrm{N}=$ Banyak Pertanyaan

$\mathrm{f}=$ Frekuensi (banyaknya pertanyaan)

$1,2,3,4,5$, atau 6 merupakan deskriptor

Selain termasuk dalam 3 dimensi kognitif TIMSS, ternyata terdapat 1 pertanyaan yang tidak dapat diklasifikasikan ke dalam 3 dimensi kognitif TIMSS. 1 soal tersebut terdapat pada soal uji kompetensi semester 1 no 29.

Jika, Perbandingan uang Ayubi, Budi, dan Candia adalah $2: 3: 5$, jika Ayubi mempunyai uang sebesar Rp10.000,00 Budi mempunyai uang sebesar Rp15.000,00

Pertanyaan tersebut tidak dapat diklasifikasikan karena menurut peneliti, pertanyaan tersebut masih kurang atau belum lengkap. Sehingga maksud yang ingin dicapai pertanyaan tersebut tidak dapat dimengerti. Adapun persentasenya yaitu sebesar $0,6 \%$.

Menurut TIMSS 2011 Assessment Frameworks, persentase untuk tiap dimensi kognitif TIMSS di kelas empat yaitu 40\% domain pengetahuan, 40\% domain penerapan dan $20 \%$ domain penalaran. Persentase dimensi kognitif TIMSS di kelas delapan yaitu 35\% domain 
pengetahuan, $40 \%$ domain penerapan dan $25 \%$ domain penalaran. Persentase target tersebut dapat dilihat pada Tabel 3 berikut.

Tabel 3 Tabel Hasil yang Ditargetkan TIMSS untuk Kelas IV dan VIII

\begin{tabular}{|clcc|}
\hline \multirow{2}{*}{ Dimensi } & \multirow{2}{*}{ Domain } & \multicolumn{2}{c|}{ Persentase } \\
\cline { 3 - 4 } & & Kelas IV & Kelas VIII \\
\hline \multirow{3}{*}{ Kognitif } & Pengetahuan (Knowing) & $40 \%$ & $35 \%$ \\
\cline { 2 - 4 } & Penerapan (Applying) & $40 \%$ & $40 \%$ \\
\cline { 2 - 4 } & Penalaran (Reasoning) & $20 \%$ & $25 \%$ \\
\hline
\end{tabular}

Berdasarkan Tabel 3, dapat disimpulkan bahwa untuk kelas VII persentase tiap dimensi kognitif seharusnya tidak terpaut jauh dari dimensi kognitif yang harus dicapai kelas VIII. Namun berdasarkan hasil analisis terdapat hal yang kurang sesuai. Karena pertanyaan yang termasuk dalam domain penalaran kurang dari target. Berdasarkan penelitian, didapat bahwa siswa tidak diberikan tantangan untuk menyelesaikan permasalahan-permasalahan yang kompleks yang menuntut kreativitas, berpikir kritis dan analitis dalam menyelesaikan masalah. Padahal kemampuan berfikir kreatif, berpikir kritis dan analitis sangat diperlukan dalam menyelesaikan permasalahan-permasalahan yang akan dihadapi siswa di kemudian hari. Selain itu, kemampuan berpikir kritis, kreatif, dan analitis diperlukan untuk mampu bersaing dalam dunia global. Jika hal ini tidak segera dicarikan solusi yang tepat, maka sumber daya manusia bangsa Indonesia akan semakin tertinggal jauh dari negara lain bahkan sesama negara ASEAN. Untuk menanggulangi permasalahan tersebut, dan khususnya untuk menyempurnakan buku siswa matematika kurikulum 2013 kelas VII semester 1 (edisi revisi 2014), maka dibutuhkan penambahan pertanyaan yang termasuk ke dalam domain penalaran. Hal ini dilakukan dengan harapan agar dapat meningkatkan peringkat matematika siswa Indonesia pada pelaksanaan TIMSS dan perbaikan pendidikan di Indonesia.

\section{Kesimpulan dan Saran}

\section{Kesimpulan}

Buku Siswa Matematika Kurikulum 2013 untuk

Sekolah Menengah Pertama kelas VII semester 1 (edisi revisi 2014) ini merupakan buku yang dipersiapkan pemerintah dalam rangka implementasi kurikulum 2013. Pada buku ini terdapat 85 soal dan 177 pertanyaan yang tersebar pada uji kompetensi yang terdapat di tiap pokok bahasan serta uji kompetensi semester 1. Berdasarkan hasil analisis data dan pembahasan yang telah dilakukan, maka dapat diambil beberapa kesimpulan sebagai berikut.

1. Persentase soal yang sesuai deskriptor pada setiap domain berdasarkan dimensi kognitif TIMSS pada Buku Siswa Matematika Kurikulum 2013 untuk Sekolah Menengah Pertama kelas VII semester 1 (edisi revisi 2014) adalah:

a. Domain pengetahuan yang terbagi atas 2,82\% deskriptor A2 (mengenali); 7,35\% deskriptor A3 (menghitung); 12,43\% deskriptor (mengambil); $16,38 \%$ deskriptor (mengklasifikasikan/mengurutkan).

b. Domain penerapan yang terbagi atas $25,4 \%$ deskriptor B1 (memilih); 9,6\% deskriptor B2 (menunjukkan);
7,35\% deskriptor B3 (memodelkan); 0,6\% deskriptor B4 (mengimplementasikan); 7,9\% deskriptor B5 (memecahkan masalah rutin).

c. Domain penalaran yang terbagi atas 3,38\% deskriptor $\mathrm{C} 1$ (menganalisis); $4,52 \%$ deskriptor $\mathrm{C} 3$ (mengintegrasi /menyatukan); 1,69\% deskriptor C4 ( membenarkan).

d. $0,6 \%$ lain-lain.

2. Berdasarkan dimensi kognitif TIMSS soal-soal uji kompetensi pada buku ini mencakup 38,98\% domain pengetahuan (A), 50,85\% domain penerapan (B), 9,6\% domain penalaran $(\mathrm{C})$, dan $0,6 \%$ lain-lain. Sehingga soal-soal uji kompetensi dalam buku siswa matematika kurikulum 2013 untuk SMP kelas VII semester 1 (edisi revisi 2014) didominasi oleh domain penerapan (B).

\section{Saran}

Berdasarkan hasil penelitian mengenai analisis soal dalam Buku Siswa Matematika Kurikulum 2013 untuk SMP Kelas VII semester 1 (edisi revisi 2014) berdasarkan dimensi kognitif TIMSS, maka demi bermanfaatnya penelitian ini penulis ingin memberikan beberapa saran sebagai berikut:

Hasil dari analisis buku ini dapat digunakan sebagai acuan dalam memilih soal pada buku siswa yang sesuai bagi pembelajaran di era Kurikulum 2013 ini.

2. Bagi penulis dan penerbit buku teks matematika kelas VII, hasil akhir dari penelitian ini dapat dijadikan bahan masukan dalam merevisi buku siswa matematika selanjutnya terutama dalam hal pembuatan dan pemilihan soal agar komposisinya tidak terpaut jauh dengan target yang ingin dicapai dimensi kognitif TIMSS. Oleh karena itu, sebaiknya banyaknya soal yang termasuk dalam domain penalaran pada buku siswa yang diteliti dalam penelitian ini ditambah. Agar kemampuan berfikir kreatif, berfikir kritis dan analitis siswa yang diperlukan untuk mampu bersaing dalam dunia global dapat meningkat.

\section{Daftar Pustaka}

[1] Hamalik, Dr. Oemar. 2011. Kurikulum dan Pembelajaran. Jakarta: Bumi Aksara Hamalik.

2] Mullis, Ina V.S., Martin, M.O., gonzalez, eugenio j., gregory kelvin d., garden, robert a., o'connor, kathleen m., chrostowski, steven j., \& smith, teresa a..2000. TIMSS 1999 International Mathematics Report Findings From Iea's Repeat Of The Trends International Mathematics and Science Study At The Eighth Grade, Chestnut Hill, USA: TIMSS \& PIRLS International Study Center, Boston College. Ttg urutan kognitif TIMSS tahun 1999.

[3] Mullis, Ina V.S., Martin, M.O., \& foy, p. 2005. IEA's TIMSS 2003 International Report On Achievement In The Mathematics Cognitive Domains Findings From A Developmental Project, Chestnut Hill, USA: TIMSS \& PIRLS International Study Center, Boston College. Ttg urutan kognitif TIMSS tahun 2003

[4] Mullis, Ina V.S., Martin, M.O., Foy, P., Olson, J.F., Preuschoff, C., Erberber, E., Arora, A., \& Galia, J. 2008. TIMSS 2007 International Mathematics Report: Findings from IEA's Trends in International Mathematics and Science Study at the Fourth and Eighth Grades. Chestnut Hill, MA: TIMSS \& PIRLS International Study Center, Boston College Ttg urutan kognitif TIMSS tahun 2007.

[5] Mullis, Ina V.S., Martin, M.O., \& foy, p. 2012. IEA's TIMSS 2011 International Report On Achievement In The Mathematics Cognitive Domains Findings From A Developmental Project, Chestnut Hill, USA: TIMSS \& PIRLS International Study Center, Boston College. Ttg urutan kognitif TIMSS tahun 2011

[6] Mullis, Ina V.S. Martin, Michael O., Ruddock, Graham J., O'Sullivan, Christine Y., Arora, Alka., Erberber, \& Ebru. 2009. The 
TIMSS 2011 Assessment Frameworks. Boston College, USA : TIMSS \& PIRLS International Study Centre.

[7] Permendikbud. 2013. No. 68 th 2013 ttg KD dan Struktur Kurikulum SMPMTs. Jakarta: Depdiknas

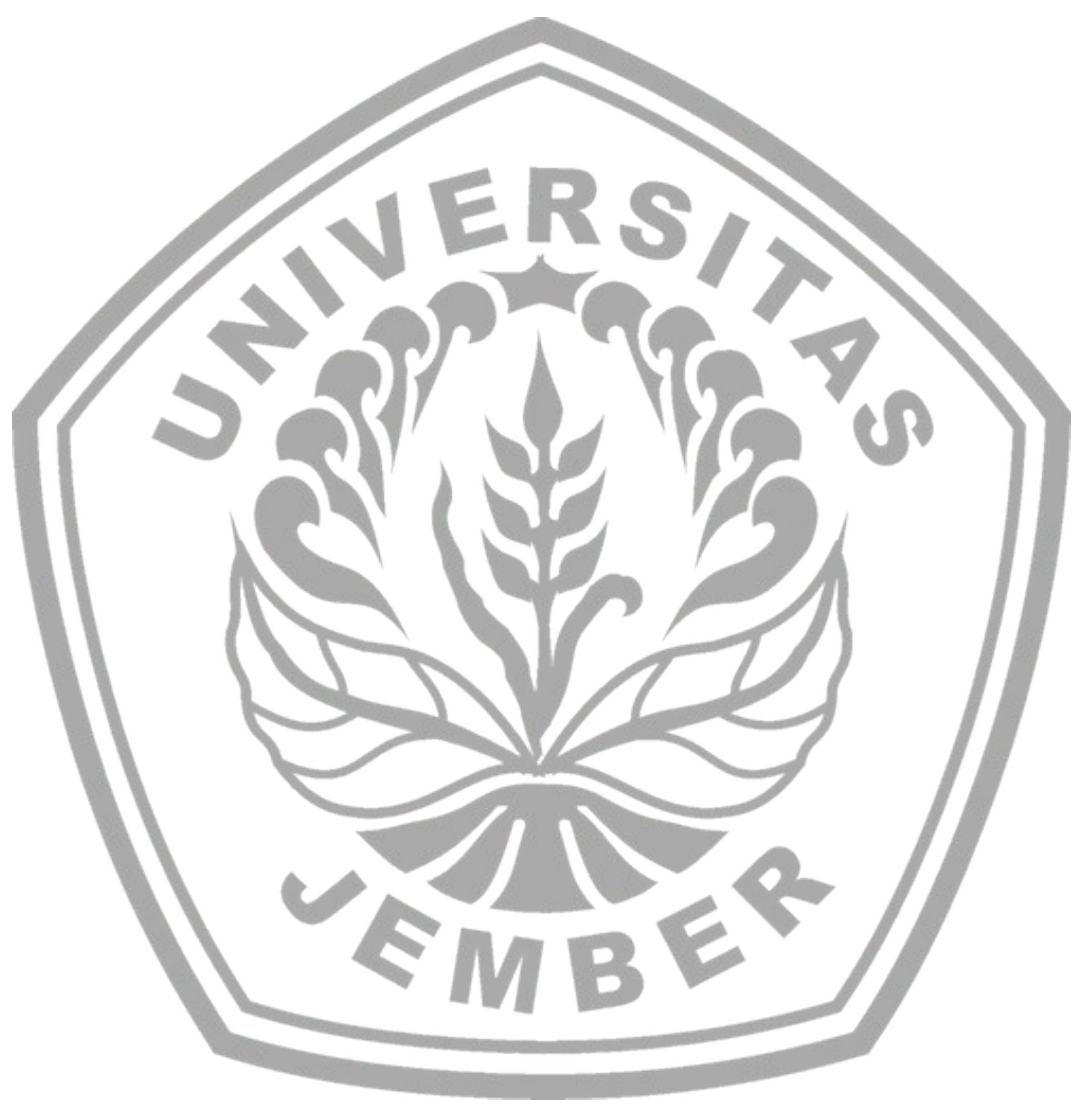

